\title{
Water Diffusion Barrier - A Novel Design for High Voltage Subsea Cables
}

\author{
Knut Magne Furuheim, Susanne Nilsson ${ }^{1}$ \\ Sverre Hvidsten, Svein Magne Hellesø ${ }^{2}$ \\ 1. Nexans Norway AS, Halden, Norway \\ 2. SINTEF Energy Research, Trondheim, Norway
}

\begin{abstract}
High voltage subsea cables are normally sheathed with a metallic water barrier at voltage levels above $36 \mathrm{kV}$ as recommended by the standards (IEC 60840). The main concern with water ingress in power cables is the risk of water tree formation. Water tree growth will reduce the lifetime of power cables. For dynamic cable designs there are today few reliable alternatives to prevent the water ingress. Here a novel electrical semi-conductive water barrier is presented, based on a multilayer polymer sheath design where the arrangement of layers is based on numerical simulations using measured water transport data.
\end{abstract}

\section{Introduction}

Water tight barriers are recommended at voltages $>36$ $\mathrm{kV}$ [1]. Water ingress into the cable insulation can induce water treeing, which is a slow degradation mechanism that lowers the dielectric strength and ultimately leads to an electric breakdown of the cable [2]. Water trees consists of water filled voids, with higher conductivity than the insulation. For water tree inception to occur a number of factors are required, i.e. electric field, water, a defect and/or a void. Other factors accelerating water tree inception and growth are: increased content of ions and contaminants, higher frequencies and amplified electric field [2, 3, 4]. Water trees can be divided into two main categories, i.e. vented water trees and bow-tie trees. Vented trees grow from either the conductor or insulation screen, and are generally considered to be the most critical water tree as it can grow to long lengths and even bridge the insulation. Vented water trees can also act as initiation points for electrical trees, which would then cause an electric breakdown. Bow-tie trees generally start at defects in the bulk of the insulation. As mentioned above, water tree inception is dependent on the presence of water. Earlier studies have shown that water tree inception can take place at defects already at $70 \%$ Relative Humidity ( $\mathrm{RH}$ ) [5]. It has also been shown that dynamic mechanical stress increases inception and growth of both bow-tie and vented trees in the strain region [6]. The development of modern insulation systems and cable designs has focused on material cleanliness, dry triple extrusion and a general focus on high quality cable designs, which have considerably decreased the problems with water treeing [7].
Except from the direct effect of water tree growth on the cable performance, it has been observed that water in Extra High Voltage (EHV) cables can cause increased losses in the material, which could be detrimental at these high voltage levels [8]. The effect is not clear as measurements on miniature cables do not reveal any increased losses at power frequency up to very high fields. The DC conductivity in the low frequency range is on the other hand strongly affected by the water absorption $[9,10]$.

The traditional water barrier in high voltage subsea cables is typically a lead sheath. For land cables, an aluminium /polymer laminate is often used. In general aluminium has poor corrosion resistance, but due to the lamination process this problem has decreased strongly. The 0.1-0.3 mm thick aluminium foil is glued longitudinally and these designs have an excellent track record [11]. Copper sheaths can also be used as a radial water barrier. One major drawback with lead is its sensitivity to fatigue, which makes lead non suitable for dynamic applications. Copper has better fatigue properties than lead, but is expensive. Advantages and disadvantages are evaluated in [12]. One possibility for dynamic applications is the novel water diffusion barrier design based on a two layer polymeric sheath previously presented in [13]. In this work a semi-conductive design is demonstrated. The main characteristic of this design is that the time to water saturation in the polymer layer is strongly delayed. Moreover, the polymeric layer will also have environmental advantages compared to lead; both due to the risk of human hazard mainly during production of the lead sheath, and due to the weight saving by replacing lead with less heavy materials. The weight savings have a substantial advantage due to increased capacity of transportation, for instance shipment, and furthermore lighter materials leads to less mechanical strain during e.g. layout of subsea cables.

\section{Design of water barrier}

The novel water barrier is based on an outer sheath of polyethylene (PE) type, where water permeability is low and an inner layer of polyurethane (PU) type with high water absorption capacity. Substantial amounts of work have been put on the design, the choice of materials and development of methods to determine the accurate data on solubility coefficient, $S$, diffusion coefficient, $D$, and permeability coefficient, $P$. The water ingress to the polymer can be described by Henry's law [14], i.e. the 
solubility of water in a polymer, $\boldsymbol{\rho}$ is directly proportional to the partial pressure of water above the polymer, $\boldsymbol{p}$ :

$\boldsymbol{\rho}=\boldsymbol{S} \cdot \boldsymbol{p}$

The diffusion is controlled by Fick's Law, which states that the mass flux, $\boldsymbol{j}$ of the diffusing species is proportional to its concentration gradient, $\nabla \boldsymbol{\rho}$ :

$j=-D \nabla \rho$

Permeability, $\mathrm{P}$, if $\mathrm{D}$ is constant is:

$P=D \cdot S$

The main innovation of the design is based on detailed material data generated by sorption trials. A numerical computational model has been developed for the calculations and this data show satisfying correlations with measured data [13]. Literature based solubility/diffusion data of liquid diffusion in polymers is often based on permeability measurements on thin films, which is proven to give deviating results for the comparably thick sheaths used in this design.

The water barrier design presented in this paper is a fully semiconducting construction. This design is preferential for many AC subsea cables, for instance Direct Electrical Heating (DEH) cables. These cables are strapped onto an oil or gas flow line, where the flow line act as a return conductor for the current, which will generate heat in the metallic pipe wall thus preventing hydrate and wax formation [15].

\section{Prototype Production}

Prototype cables with the present design have been produced for full scale evaluation and verification of the developed numerical models. Calculations show that equal thickness of the two sheaths is preferential, and therefore the design is based on two $3 \mathrm{~mm}$ layers, see Fig.1 [13]. This design, Design 1, provides strongly delayed time to saturation in the XLPE compared to only the use of an outer sheath. A second design, Design 2 , is also developed, with a thin metal/polymer laminate between the polymer layers. This design can be compared with the use of aluminium laminates in $\mathrm{HV}$ land cables as mentioned above, but with the main difference that the metallic foil is very thin to allow for dynamic motions. Small scale testing has shown good mechanical properties of the foil, with excellent resistance to deformation at strain and at fatigue testing [16]. Design 2 will provide a fully watertight construction, and is preferential when cables are operated at increased temperatures, e.g. DEH, that often operates at $90^{\circ} \mathrm{C}$. The axial conductivity of the laminate has to be low enough, for the capacitive currents to be directed radially. Another area of application for Design 2 could be cables with voltage levels $>\sim 170 \mathrm{kV}$ where Nexans internal tests have shown that even small contents of water can increase the losses. Design 2 is presented in Fig. 2.

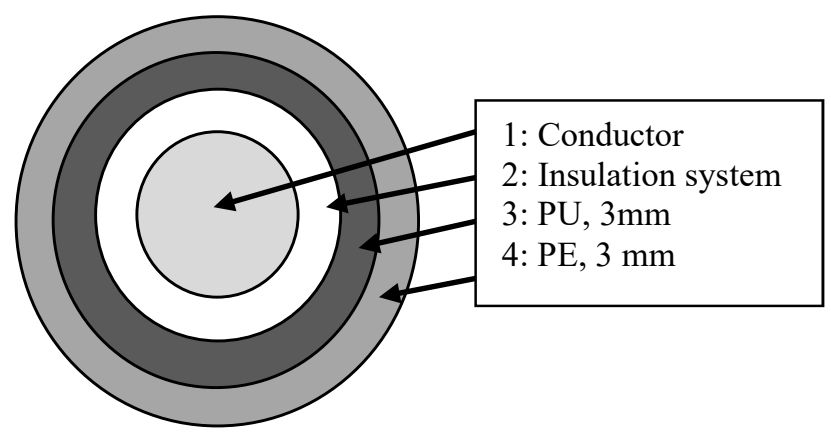

Fig. 1 - Design 1 with strongly delayed water diffusion. The insulation system is XLPE.

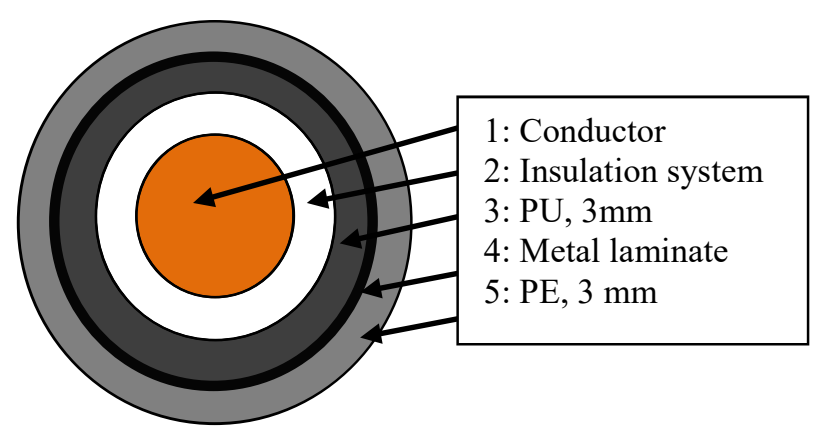

Fig. 2 - Design 2 with fully water tight construction. The insulation system is XLPE.

For the production of the two designs, optimization of the process with regards to extrusion of PU was performed. PU has very different extrusion properties compared to the more common PE materials used for sheathing. Focus was on obtaining a smooth surface of the PU to facilitate low friction between the layers in Design 1 and between PU sheath and laminate in Design 2. Concerning Design 2, the method for applying the thin laminate onto the cable also had to be revised to fit the much thinner laminate than what normally is used for $\mathrm{MV} / \mathrm{HV}$ land cables. Further optimization of Design 2 is still ongoing.

\section{Material and experimental data}

The material choices of the innovative water diffusion barrier are primarily chosen with respect to low water permeability of the outer sheath, combined with high water solubility of the inner sheath. Materials are chosen based on experimental results, obtained under more relevant conditions for our demanding applications, such as high strain, dynamic motion and temperature gradients, than data often found in literature. Selection is also based on the commercial availability of the materials, extrusion properties, hardness, electrical resistance etc. As the outer sheath will act concurrently as a water barrier and a normal 
protective sheath, the sheath has to fulfil requirements met in different standards, for instance IEC. This limits the choice of outer sheaths. Different polymer materials have large differences in water permeability and solubility properties. Even in the PE polymer family, the diffusion properties vary considerably, from fairly high permeability in LDPE and very low permeability in HDPE types. Typically the permeability could be in the range of 10 times higher in LDPE compared to HDPE [17].

In Table 1 and 2, the time to reach $70 \% \mathrm{RH}$ and $>99 \%$ $\mathrm{RH}$ at the conductor and insulation screen is shown as a function of temperature. The present material combination is compared to the use of only an outer PE sheath. The data is based on water absorption data, simulated in a numerical model.

\section{Discussion}

As stated above, it has been found that the time to water saturation is increased by around 5 times in a double layer design, compared to only using an outer PE sheath. It can also be seen that the water diffusion is strongly controlled by the temperature, where an increase in temperature from 20 to $40^{\circ} \mathrm{C}$ reduces time to water saturation with a factor of around 0.1 . Another important result is that although a $\mathrm{RH}$ of $70 \%$ could be reached within a few years at $40^{\circ} \mathrm{C}$, the time to reach $>99 \% \mathrm{RH}$ is four times longer. As stated above, the limit for water tree inception to start at $70 \% \mathrm{RH}$ origins from old measurements on small scale samples, and in reality the water tree inception and growth at this $\mathrm{RH}$ might be very limited. The insulation systems have improved significantly since the 70 s when the problems with water treeing were first detected [3]. It is well known that both improved chemical cleanliness, e.g. decreased amount of ionic species in semicons, and physical cleanliness, e.g. decreased amount of different contaminants, of the materials and the material systems have dramatically decreased the risk for water treeing, in particular for vented water trees [7]. It is probable that water tree inception takes place at around $70 \% \mathrm{RH}$ due to water condensation at contaminants such as sodium chloride particles [18]. As the number of defects, contaminants and voids are minimized in present material system also the frequency of water tree inception at $70 \% \mathrm{RH}$ should be decreased. Recent work has also shown that a temperature gradient over the insulation can lead to a case where $70 \% \mathrm{RH}$ is never reached at the insulation close to the conductor screen, thus inception of water trees can be avoided [18].

In addition to the presented designs, the safety factor of the constructions might be even further enhanced by for instance adding a layer of swelling tapes beneath the

Table 1: Time to 70 and $99 \% \mathrm{RH}$ in a cable with only the outer PE sheath, with initial 0 and $30 \% \mathrm{RH}$ in the cables, respectively

\begin{tabular}{|c|c|c|c|c|c|c|c|c|}
\hline \multirow{3}{*}{$\begin{array}{c}\text { Temperature } \\
{\left[{ }^{\circ} \mathrm{C}\right]}\end{array}$} & \multicolumn{4}{|c|}{ Initial 0\% RH } & \multicolumn{4}{|c|}{ Initial $30 \%$ RH } \\
\hline & \multicolumn{2}{|c|}{$\begin{array}{l}\text { Time to } 70 \% \text { RH } \\
\text { [years] }\end{array}$} & \multicolumn{2}{|c|}{$\begin{array}{c}\text { Time to } 99 \% \mathrm{RH} \\
\text { [years] }\end{array}$} & \multicolumn{2}{|c|}{$\begin{array}{l}\text { Time to } 70 \% \text { RH } \\
\text { [years] }\end{array}$} & \multicolumn{2}{|c|}{$\begin{array}{c}\text { Time to } 99 \% \text { RH } \\
\text { [years] }\end{array}$} \\
\hline & $\begin{array}{l}\text { Insulation } \\
\text { screen }\end{array}$ & $\begin{array}{l}\text { Conductor } \\
\text { screen }\end{array}$ & $\begin{array}{l}\text { Insulation } \\
\text { Screen }\end{array}$ & $\begin{array}{l}\text { Conductor } \\
\text { Screen }\end{array}$ & $\begin{array}{l}\text { Insulation } \\
\text { screen }\end{array}$ & $\begin{array}{l}\text { Conductor } \\
\text { screen }\end{array}$ & $\begin{array}{l}\text { Insulation } \\
\text { screen }\end{array}$ & $\begin{array}{l}\text { Conductor } \\
\text { screen }\end{array}$ \\
\hline 5 & 28 & 35 & 110 & 110 & 19 & 25 & 100 & 110 \\
\hline 10 & 14 & 17 & 54 & 57 & 9.5 & 13 & 51 & 54 \\
\hline 20 & 3.5 & 4.4 & 14 & 15 & 2.4 & 3.5 & 13 & 14 \\
\hline 40 & 0.32 & 0.41 & 1.3 & 1.4 & 2.2 & 0.31 & 1.2 & 1.3 \\
\hline 90 & 0.0028 & 0.0038 & 0.011 & 0.013 & 0.0019 & 0.0029 & 0.011 & 0.011 \\
\hline
\end{tabular}

Table 2: Time to 70 and $99 \%$ RH in a cable with double layer system, with initial 0 and $30 \%$ RH in the cables, respectively.

\begin{tabular}{|c|c|c|c|c|c|c|c|c|}
\hline \multirow{3}{*}{$\begin{array}{c}\text { Temperature } \\
{\left[{ }^{\circ} \mathrm{C}\right]}\end{array}$} & \multicolumn{4}{|c|}{ Initial 0\% RH } & \multicolumn{4}{|c|}{ Initial $30 \%$ RH } \\
\hline & \multicolumn{2}{|c|}{$\begin{array}{c}\text { Time to } 70 \% \mathrm{RH} \\
\text { [years] }\end{array}$} & \multicolumn{2}{|c|}{$\begin{array}{c}\text { Time to } 99 \% \text { RH } \\
\text { [years] }\end{array}$} & \multicolumn{2}{|c|}{$\begin{array}{c}\text { Time to } 70 \% \mathrm{RH} \\
\text { [years] }\end{array}$} & \multicolumn{2}{|c|}{$\begin{array}{c}\text { Time to } 99 \% \mathrm{RH} \\
\text { [years] }\end{array}$} \\
\hline & $\begin{array}{l}\text { Insulation } \\
\text { screen }\end{array}$ & $\begin{array}{c}\text { Conductor } \\
\text { screen }\end{array}$ & $\begin{array}{l}\text { Insulation } \\
\text { Screen }\end{array}$ & $\begin{array}{l}\text { Conductor } \\
\text { Screen }\end{array}$ & $\begin{array}{l}\text { Insulation } \\
\text { screen }\end{array}$ & $\begin{array}{l}\text { Conductor } \\
\text { screen }\end{array}$ & $\begin{array}{l}\text { Insulation } \\
\text { screen }\end{array}$ & $\begin{array}{l}\text { Conductor } \\
\text { screen }\end{array}$ \\
\hline 5 & 160 & 160 & 600 & 600 & 110 & 110 & 540 & 540 \\
\hline 10 & 76 & 79 & 290 & 300 & 54 & 57 & 280 & 280 \\
\hline 20 & 20 & 21 & 76 & 79 & 14 & 15 & 70 & 73 \\
\hline 40 & 1,8 & 1,8 & 6,7 & 6,7 & 1,2 & 1,3 & 6,3 & 6,3 \\
\hline 90 & 0,018 & 0,019 & 0,063 & 0,067 & 0,013 & 0,014 & 0,06 & 0,06 \\
\hline
\end{tabular}


sheaths, or increase the thickness of the sheaths. A powerful tool for development of new water barrier designs is the combination of the comprehensive data from experimental water transport characterization of the cable materials and the developed numerical simulation model [19].

\section{Future work}

There are no standards covering this type of multifunctional sheath, which will act concurrently as a water barrier and a mechanical protective cable sheath. As the aim is to produce complete outer sheath system solutions for all types of cables ranging from MV to EHV level, a comprehensive qualification work has been started. This work includes a full validation of the numerical simulations of water ingress on small scale samples, and adaption of the model to full scale samples. Much focus will also be put on the qualification of the water barrier properties of the sheathing system during dynamic movements and electrical and long term testing under relevant service conditions. Existing standards of water barriers and protective sheaths will be used as a reference. Last, but not least, a full cable system also including repair and factory joints will be qualified.

\section{Acknowledgment}

This work is a part of the Norwegian Research Council project 225895/E20 supported by the Norwegian Research Council, Nexans Norway and Statnett with Sintef Energy Research as the research partner.

\section{References}

[1] IEC 60840: Power cables with extruded insulation and their accessories for rated voltages above 30 $\mathrm{kV}$ up to $150 \mathrm{kV}$ - Test methods and requirements. 3rd edition, 2004.

[2] J. Jow and R. M. Eichhorn, “Water treeing," in Wiley Encyclopedia of Electrical and Electronics Engineering, Ed. John G. Webster, New York: John Wiley \& Sons, Inc, 1999.

[3] L. A. Dissado and J. Fothergill, Electrical degradation and breakdown in polymers. Peter Peregrinus Ltd, London, 1992.

[4] J. Fothergill, A. Eccles, A. Houlgreave, and L. A. Dissado, "Water tree inception and its dependence upon electric field, voltage and frequency," IEE Proceedings Science, Measurement and Technology, vol. 140, no. 5, pp. 397-403, 1993.

[5] J. Sletbak and A. Botne, "A study of inception and growth of water trees and electrochemical trees in polyethylene and cross linked polyethylene insulations," IEEE Trans. Elect. Insulation, vol. EI-12, no. 6, pp. 383-389, Dec. 1977

[6] S. Nordås and E. Ildstad, "The influence of strain on water treeing in XLPE power cables," 10th
IEEE International Conference on Solid Dielectrics (ICSD), 2010 , pp.1,4, 4-9 July 2010

[7] N. Hampton, R. Hartlein, H. Lennartsson, H. Orton ans R. Ramachandran, "Long-life XLPE Insulated Power Cable," Jicable 2007

[8] Internal knowledge

[9] S. Hvidsten and F. Satre, "Dielectric response of sPP and XLPE insulations at high temperatures and electric fields," 2011 Annual Report Conference on Electrical Insulation and Dielectric Phenomena (CEIDP), pp.695,698, 16-19 Oct. 2011

[10] T.A Ve,. F. Mauseth, and E. Ildstad, "Effect of water content on the conductivity of XLPE insulation," 2012 Annual Report Conference on Electrical Insulation and Dielectric Phenomena (CEIDP), pp.649,653, 14-17 Oct. 2012

[11] T Worzyk. Submarine power cables. Design, Installation, Repair, Environmental Aspects, Springer, 1999

[12] B. Sonerud, F. Eggertsen, S. Nilsson, K-M. Furuheim and G. Evenset., "Material considerations for submarine high voltage XLPE cables for dynamic applications," 2012 Annual Report Conference on Electrical Insulation and Dielectric Phenomena (CEIDP), pp.890,893, 1417 Oct. 2012

[13] S. M. Hellesø, S. Hvidsten, G. Balog, K. M. Furuheim, "Calculation of Water Ingress in a HV Subsea XLPE Cable with a Layered Water Barrier Jacket System", Journal of Applied Polymer Science. Vol. 121, Issue 4, pages 2127-2133, 15 August 2011

[14] J. Crank and G.S. Park, Diffusion in polymers, Academic Press, London, 1968.

[15] S. Hvidsten, J.K. Lervik, H. Kullbotten, J.T. Benjaminsen, K. Olafsen, L.M. Lundegaard, and A. Bornes, "HV cable design applicable for direct electrical heating of very long flowlines," Oceans '04. MTTS/IEEE techno-ocean vol.1, pp.257, 263, 9-12 Nov. 2004

[16] Internal report

[17] W.W. Muller, HDPE geomembranes in geotechnics, Springer, New York, 2007

[18] S. M. Hellesø, S. Hvidsten, K. M. Furuheim and G. Håkonseth,"Water treeing in subsea XLPE cables with thermal gradient", To be published at 2013 IEEE Electrical Insulation Conference, June 2013, Ottawa, Canada

[19] NFR project 192900/S60, "Utvikling og evaluering av ulike barrieresystem for statiske og dynamiske sjøkabler", 2009-2012. 